\title{
EVALUASI DAN PENGEMBANGAN PROGRAM PELATIHAN SDM MELALUI KETERAMPILAN KERJA DALAM UPAYA PENINGKATAN KINERJA KARYAWAN DI PT. PUPUK ISKANDAR MUDA
}

\author{
Nani Vivi Yanti ${ }^{1}$, Sukaria Sinulingga ${ }^{2}$, Harmein Nasution $^{3}$ \\ Departemen Teknik Industri, Fakultas Teknik, Universitas Sumatera Utara \\ Jl. Almamater Kampus USU, Medan 20155 \\ Email: naniviviyanti86@gmail.com
}

\begin{abstract}
Abstrak. Peningkatan kinerja perusahaan merupakan suatu keharusan bagi perusahaan agar dapat berdaya saing. Dalam meningkatkan kinerjanya perusahaan dituntut membekali karyawannya supaya semakin terampil dalam bekerja. Untuk meningkatkan keterampilan kerja karyawan salah satunya dapat dilakukan dengan pelatihan. Penyelenggaraan pelatihan dikatakan berhasil jika berdampak bagi peningkatan keterampilan kerja karyawan yang pada akhirnya juga meningkatkan kinerja. Ada empat faktor yang mempengaruhi keberhasilan pelatihan, yaitu: instruktur pelatihan, bahan pelatihan, metode pengajaran, dan fasilitas pelatihan. Penelitian ini ingin mengetahui dampak pelatihan terhadap keterampilan kerja dan kinerja. Untuk mengetahui dampaknya dilakukan evaluasi pelatihan. Evaluasi diawali dengan menyusun instrumen penilaian kemudian dilanjutkan dengan penilaian dalam lima tahapan, yaitu: 1) evaluasi penyelenggaraan pelatihan, 2) evaluasi proses pembelajaran, 3) evaluasi aplikasi pada pekerjaan, 4) evaluasi dampak bagi kinerja perusahaan, dan 5) evaluasi dampak biaya pelatihan dengan pendapatan perusahaan. Data penelitian diperoleh dari penyebaran kuesioner terhadap 68 karyawan yang mengikuti pelatihan, pengumpulan dokumen dan laporan perusahaan. Hasil penelitian menunjukkan bahwa komponen pelatihan yang mempengaruhi keterampilan kerja adalah instruktur pelatihan $(0,277)$, bahan pelatihan $(0,575)$, metode pengajaran $(0,545)$, dan fasilitas pelatihan $(0,423)$. Hal ini sesuai dengan hasil evaluasi yang menunjukkan bahwa peningkatan rata-rata instruktur pelatihan $2,5 \%$, bahan pelatihan $3,5 \%$, metode pengajaran $1,8 \%$, dan fasilitas pelatihan 3,9\% tiap tahunnya juga meningkatkan keterampilan kerja sebesar $0,4 \%$. Dari uji statistik diketahui bahwa keterampilan kerja mempengaruhi kinerja sebesar 0,282. Namun, berdasarkan hasil evaluasi diketahui bahwa pelatihan yang mempengaruhi keterampilan tidak berpengaruh terhadap kinerja. Peningkatan keterampilan kerja sebesar 0,4\% tiap tahunnya, menghasilkan kinerja yang fluktuatif tiap tahunnya.
\end{abstract}

Kata Kunci: Kinerja, Keterampilan Kerja, Pelatihan dan Evaluasi Pelatihan

\begin{abstract}
An increase in the company performance is a necessity for the company in order to defenseless competitiveness. To improve their performance company prosecuted in employees that the skilled in work. To increase work skills employees one of which may be done by training. Of training be assessed as being successful if impact on increasing work skills employee who in the end also improve the performance. There are four of factors affect the success of training,: instructors training, the training materials, a method of teaching, and training facility. To know the impact assessment training. Evaluation started by putting together an instrument assessment and continued with of the scoring in your five steps, namely: 1 evaluating the implementation of training, 2) evaluation learning, 3) evaluation application on the job, 4) impact evaluation for the company performance, and 5) impact evaluation the cost of training and its revenue. Lab data obtained from the spread of the questionnaire to 68 employee who follow the training, collecting documents and report company. The research results show that component training that affects work skills is instructors the (0,277), material the (0,575), a method of teaching (0,545), and facilities the (0,423). This is in accordance with the evaluation show that the increase in the average instructors training $2.5 \%$, the training materials $3.5 \%$, a method of teaching $1.8 \%$, and training facility $3.9 \%$ every year also improve work skills $0.4 \%$. Of statistical tests be seen that work skills influences the performance of 0,282. But, based on the evaluation of known that the training that affects skill has not been affecting the performance. An increase in work skills $0.4 \%$ every year, produce performance been fluctuating every year.
\end{abstract}

Keywords: Performance, Skills, Training and Evaluation Training

\footnotetext{
${ }^{1}$ Mahasiswa Sekolah Pascasarjana Departemen Teknik Industri Fakultas Teknik Universitas Sumatera Utara

2 Dosen Departemen Teknik Industri Fakultas Teknik Universitas Sumatera Utara

${ }^{3}$ Dosen Departemen Teknik Industri Fakultas Teknik Universitas Sumatera Utara
} 


\section{PENDAHULUAN}

Sumber daya manusia mempunyai peranan penting bagi perusahaan, karena memiliki bakat, tenaga dan kreativitas yang dibutuhkan untuk menggerakkan perusahaan. Oleh sebab itu, perusahaan harus memberikan perhatian secara maksimal pada pegawainya, baik perhatian dari segi kualitas pengetahuan dan keterampilan, maupun tingkat kesejahteraannya, sehingga pegawai yang bersangkutan dapat terdorong untuk memberikan segala kemampuan sesuai dengan yang dibutuhkan perusahaan.

Peningkatan kemampuan, pengetahuan, dan keterampilan pegawai dapat melalui program pelatihan dan pengembangan, terutama untuk menghadapi perkembangan teknologi yang demikian pesat. Penyelenggaraan program pelatihan dan pengembangan harus disesuaikan dengan kebutuhan jenis pekerjaan dan kemampuan karyawan dalam mengikutinya, hal ini tentu tidak terlepas dari materi dan metode yang digunakan.

Untuk melihat efektifitas program pelatihan dan pengembangan, maka perusahaan perlu melakukan penilaian terhadap perubahan sikap dan keterampilan para karyawan, baik sebelum maupun sesudah mengikuti program pelatihan dan pengembangan sehingga diharapkan dapat meningkatkan kinerja karyawan. Banyak usaha yang dilakukan untuk meningkatkan kinerja, diantaranya melalui kegiatan pelatihan.

PT. Pupuk Iskandar Muda adalah suatu perusahaan yang bergerak dalam bidang industri pupuk urea dan industri kimia lainnya, dan mempunyai karyawan sebanyak 1.053 orang. Pupuk urea merupakan salah satu produk strategis yang sangat penting peranannya dalam menunjang produksi pertanian. PT. Pupuk Iskandar Muda memiliki SDM yang menjadi salah satu faktor penting yang sangat berperan untuk dapat menjalankan perusahaan secara optimal. Saat ini PT. Pupuk Iskandar Muda memiliki 2 unit pabrik yang memproduksi urea jenis prill (butiran) dan granule (tablet) yang masingmasing berkapasitas sama. Kedua jenis urea itu diproyeksikan dapat mensuplai pupuk nasional setiap tahun dan bahkan dapat mengekspor melalui fasilitas pelabuhan sendiri.

Pelatihan berperan penting dalam proses memperoleh dan meningkatkan kualitas kerja karyawan. Melalui pelatihan, karyawan dipersiapkan untuk memiliki bekal yang cukup agar dapat memecahkan masalah yang akan dihadapinya dimasa yang akan datang. Dalam meningkatkan kemampuan atau keahlian kerja para karyawan, perusahaan harus menjalankan usaha-usaha untuk mengembangkan karyawannya.

\section{METODE PENELITIAN}

Metode penelitian merupakan tahapan-tahapan, petunjuk pelaksanaan, atau petunjuk teknis dalam melakukan pencarian masalah, penentuan solusi, dan mencari solusi dari masalah penelitian. Kerangka pikir merupakan gambaran proses berpikir dalam memecahkan permasalahan penelitian.

\subsection{Variabel Penelitian}

Pada penelitian ini terdapat dua variabel, yaitu sebagai berikut:

1. Variabel Dependen.

Variabel dependen merupakan variabel yang nilai atau valuenya dipengaruhi atau ditentukan oleh nilai variabel lain. Variabel dependen dalam penelitian ini adalah keterampilan kerja dan kinerja.

2. Variabel Independen.

Variabel independen merupakan variabel yang mempengaruhi variabel dependen baik secara positif maupun secara negatif. Variabel independen dalam penelitian ini adalah instruktur pelatihan, bahan pelatihan, metode pengajaran, fasilitas pelatihan.

Penelitian dapat terlaksana secara terstruktur dan menjadi lebih mudah apabila tersedia kerangka konseptual penelitian yang akan dilakukan. Kerangka konseptual dalam penelitian ini dapat dilihat seperti pada Gambar 1 di bawah ini:

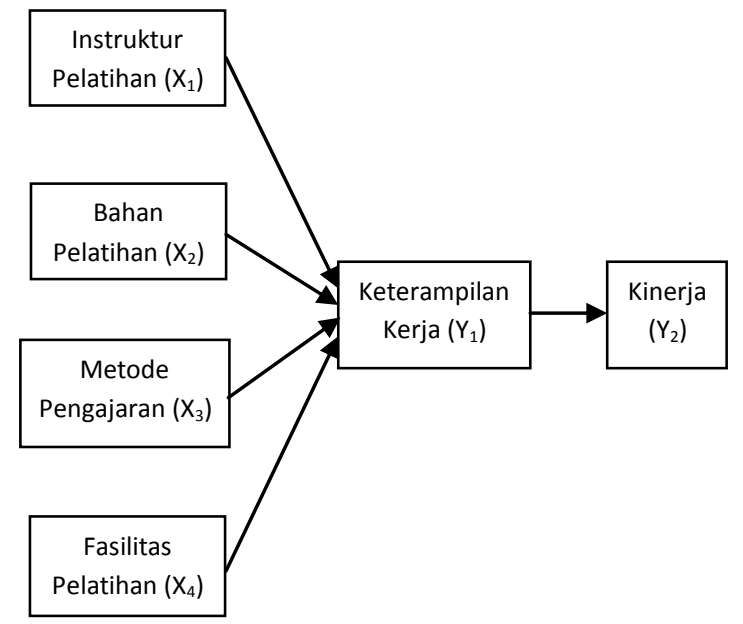

Gambar 1. Kerangka Konseptual Penelitian

\subsection{Metode Pengumpulan Data}

Data yang dikumpulkan ada dua jenis yaitu:

1. Data Primer merupakan data yang diperoleh secara langsung dengan cara memberikan daftar pertanyaan (questionnaire), dan melakukan wawancara (interview) dengan karyawan PT. Pupuk Iskandar Muda.

2. Data Sekunder adalah data yang diperoleh dari dokumen perusahaan meliputi gambaran umum perusahaan, struktur organisasi, data pelatihan, data 
produksi, data keuangan dan data lainnya yang diperoleh dari pihak PT. Pupuk Iskandar Muda.

\subsection{Metode Pengolahan Data}

Pengolahan data dilakukan berdasarkan model penelitian dengan mengolah data hasil survei yang diperoleh dari penyebaran kuesioner penelitian:

1. Uji normalitas digunakan untuk memperoleh informasi mengenai distribusi data masing-masing variabel apakah normal atau tidak. Pengujian normalitas dilakukan dengan uji Kolmogorov Smirnov terhadap nilai residual menggunakan software SPSS versi 19.

2. Pengujian Linieritas dilakukan untuk mengetahui apakah hubungan variable - variabel tersebut linier.

3. Analisis Korelasi digunakan untuk mengetahui keeratan hubungan antara dua variabel. Besarnya koefisien korelasi antara nol sampai \pm 1 . Nilai positif atau negatif menunjukkan arah hubungan apakah searah atau berlawanan.

4. Analisis deskriptif digunakan sebagai alat untuk mengukur/menilai pelatihan terhadap kinerja individu dan perusahaan berdasarkan persepsi responden. Responden umumnya setuju indikatorindikator tersebut digunakan sebagai alat untuk mengukur apakah pelatihan mampu meningkatkan keterampilan kerja individu pegawai dan perusahaan, yang pada akhirnya akan mampu meningkatkan kinerja perusahaan.

\section{HASIL DAN PEMBAHASAN}

3.1. Analisis Data

Nilai linieritas masing-masing hubungan variabel dapat dilihat pada Tabel 1. berikut.

Tabel 1. Hasil Pengujian Linieritas

\begin{tabular}{cccc}
\hline $\begin{array}{c}\text { Hubungan } \\
\text { Variabel }\end{array}$ & Linearity & $\begin{array}{c}\text { Deviation } \\
\text { from } \\
\text { Linearity }\end{array}$ & Keputusan \\
\hline $\mathrm{IP}-\mathrm{Ki}$ & 0,005 & 0,287 & Hubungan \\
$\mathrm{BP}-\mathrm{Ki}$ & 0,003 & 0,110 & linier \\
$\mathrm{MP}-\mathrm{Ki}$ & 0,000 & 0,190 & Hubungan \\
$\mathrm{FP}-\mathrm{Ki}$ & 0,029 & 0,146 & linier \\
$\mathrm{KK}-\mathrm{Ki}$ & 0,020 & 0,301 & $\begin{array}{c}\text { Hubungan } \\
\text { linier }\end{array}$ \\
& & & Hubungan \\
& & & linier \\
& & & Hubungan \\
& & & linier \\
\hline
\end{tabular}

Berdasarkan tabel 1 di atas uji f. Nilai linearity untuk semua hubungan variabel lebih kecil dari 0,05. Sedangkan nilai deviation from linearity untuk semua hubungan variabel lebih besar dari 0,05 , sehingga dapat diperoleh kesimpulan bahwa terdapat hubungan linier antar variabel (IP- Ki, BP-Ki, MP-Ki, FP-Ki, dan KK$\mathrm{Ki})$.

\subsection{Evaluasi Pelatihan}

Langkah awal dalam penelitian evaluatif adalah dengan membuat kisi-kisi persiapan penyusunan instrumen. Instrumen yang disusun harus dapat menggambarkan secara utuh kegiatan evaluasi. Langkahlangkah penelitian evaluatif untuk penyusunan instrumen adalah:

1. Identifikasi Komponen.

2. Identifikasi Indikator.

3. Identifikasi Bukti-bukti.

4. Menentukan Sumber Data.

5. Menentukan Metode Pengumpulan Data.

6. Menentukan Instrumen Pengumpulan Data.

Komponen yang telah diidentifikasi kemudian digunakan untuk melakukan identifikasi indikatorindikator, kemudian ditentukan bukti-bukti untuk penyusunan kisi-kisi instrumen penelitian evaluatif. Secara garis besar sumber data dapat dibedakan menjadi 3 (tiga), yaitu: person (manusia), paper (dokumen), dan place (tempat). Mengumpulkan data dari dokumen dilakukan dengan cara mencermati apa yang tersurat dalam dokumen tersebut.

Penyelenggaraan pelatihan dapat dinilai dari hasil angket kepada peserta, hasil pengamatan dari lapangan, pencermatan dokumen dan kesimpulan wawancara. Persentase rata-rata hasil penilaian setiap instrumen dapat dilihat pada Tabel 2.

Tabel 2. Hasil Penilaian Penyelenggaraan Pelatihan

\begin{tabular}{|c|c|c|c|c|c|}
\hline \multirow{2}{*}{$\begin{array}{c}\text { Tahun } \\
\text { Penilaian }\end{array}$} & \multicolumn{4}{|c|}{ Hasil Penilaian (Persentase) } & \multirow{2}{*}{$\begin{array}{l}\text { Rata- } \\
\text { rata }(\%)\end{array}$} \\
\hline & IP & BP & MP & FP & \\
\hline 2009 & 75,11 & 70,45 & 79,49 & 73 & 74,51 \\
\hline 2010 & 75,89 & 72,73 & 82,05 & 76 & 76,67 \\
\hline 2011 & 76,07 & 75,76 & 84,62 & 77 & 78,36 \\
\hline 2012 & 79,54 & 79,21 & 83,88 & 80 & 80,66 \\
\hline 2013 & 82,36 & 80,84 & 85,26 & 85 & 83,37 \\
\hline
\end{tabular}

Berdasarkan tabel 2 di atas dapat dilihat bahwa penyelenggaraan pelatihan setiap tahunnya mengalami peningkatan rata-rata 3\%. Hanya mengalami sedikit penurunan di hasil pencermatan pada tahun 2012. Ratarata hasil penilaian tahunan terendah pada tahun awal penelitian yaitu tahun 2009 sebesar $74,51 \%$, sedangkan hasil penilaian tertinggi pada tahun 2013 sebesar 83,37\%.

Hasil penilaian dampak pelatihan terhadap kinerja perusahaan dapat dilihat pada Tabel 3. berikut ini. 
Tabel 3. Hasil Penilaian Dampak Pelatihan terhadap Kinerja Perusahaan

\begin{tabular}{cccccc}
\hline \multirow{2}{*}{$\begin{array}{c}\text { Tahun } \\
\text { penilaian }\end{array}$} & $\begin{array}{c}\text { Pendapatan } \\
\text { / biaya } \\
\text { produksi }\end{array}$ & $\begin{array}{c}\text { Laba/ } \\
\text { Rugi } \\
\text { (Rp) }\end{array}$ & \begin{tabular}{c} 
Juta \\
\cline { 4 - 5 }
\end{tabular} & Uroduksi (ton) & Amonia \\
\hline 2009 & 3,87 & -350.006 & 447.182 & 317.973 \\
2010 & 4,15 & -79.997 & 398.835 & 284.569 \\
2011 & 5,76 & 195.779 & 478.701 & 362.859 \\
2012 & 5,24 & 143.959 & 532.069 & 357.460 \\
2013 & 4,76 & 134.669 & 392.903 & 315.817 \\
\hline
\end{tabular}

\subsection{Rekomendasi Perbaikan}

Berikut ini adalah beberapa rekomendasi perbaikan pelatihan yang dapat dilakukan:

1. Jenis pelatihan yang ada saat ini lebih kearah pelatihan manajerial. Dari data pelatihan diketahui bahwa $60,1 \%$ peserta mengikuti pelatihan manajerial, 3,5\% pelatihan purnatugas, 4,9\% pelatihan sertifikasi dan $31,5 \%$ pelatihan teknik.

2. Penyusunan materi pelatihan teknik khususnya bagaimana mengembangkan proses produksi yang efektif dan efisien perlu melibatkan bagian produksi, sehingga pelatihan dapat diaplikasikan secara langsung dalam pekerjaan dilapangan.

3. Penyusunan instrumen evaluasi pelatihan setiap awal tahun dengan langkah-langkah penilaian sebagai berikut:

1. Menentukan standar dan sasaran tiap jenis pelatihan.

2. Menetapkan indikator dan skala pengukuran.

3. Melakukan standarisasi terhadap indikator pelatihan.

4. Melakukan standarisasi terhadap indikator keterampilan kerja

5. Melakukan standarisasi dalam melakukan penilaian kinerja.

6. Mengkomunikasikan standar pengukuran terhadap karyawan sebagai objek pengukuran.

4. Tolak ukur penilaian diarahkan dalam empat kelompok kategori menurut Kirkpatrick, yaitu:

1. Reaction (Reaksi).

2. Learning (Pembelajaran).

3. Behavior (Perilaku).

4. Result (Hasil).

5. Karir adalah semua pekerjaan atau jabatan yang dipegang selama masa kerja seseorang. Karir menunjukkan perkembangan para karyawan secara individual dalam suatu jenjang atau kepangkatan yang dapat dicapai selama masa kerjanya dalam suatu organisasi.

6. Hasil evaluasi pelatihan pada tahap tiga: dampak evaluasi terhadap hasil kerja dan tahap empat: dampak pelatihan terhadap kinerja organisasi dapat digunakan sebagai dasar untuk memberikan reward/punishment terhadap karyawan.

\section{KESIMPULAN} adalah:

Kesimpulan yang diperoleh dari hasil penelitian ini

1. Faktor-faktor yang mempengaruhi penyelenggaraan pelatihan adalah Instruktur Pelatihan, Bahan Pelatihan, Metode Pengajaran dan Fasilitas Pelatihan. Hasil penilaian penyelenggaran pelatihan yang dilakukan diperoleh hasil rata-rata persentase keberhasilannya adalah: $74,51 \%$ tahun 2009, $76,67 \%$ tahun $2010,78,36 \%$ tahun $2011,80,66 \%$ tahun 2012, dan tahun 2013 sebesar 83,37\%. Terjadi peningkatan dalam penyelenggaraan pelatihan setiap tahunnya.

2. Hasil penilaian dampak pelatihan terhadap proses pembelajaran mengalami peningkatan tiap tahunnya. Berikut adalah rata-rata persentase hasil penilaian tiap tahunnya, yaitu: $89,07 \%$ tahun 2009 , $89,83 \%$ tahun $2010,90,13 \%$ tahun $2011,90,71 \%$ tahun 2012, dan tahun 2013 sebesar 91,49\%. Dapat disimpulkan bahwa penyelenggaraan pelatihan yang semakin baik juga akan meningkatkan hasil penilaian proses pembelajaran.

3. Rata-rata persentase hasil penilaian aplikasi pelatihan dalam pekerjaan adalah sebagai berikut: tahun 2009 sebesar $98,65 \%$, tahun 2010 sebesar 98,67\%, tahun 2011 sebesar 98,71\%, tahun 2012 sebesar 98,94\%, dan tahun 2013 sebesar 99,23\%. Terjadi peningkatan setiap tahunnya. Ini menunjukkan bahwa pelatihan yang terselenggara dengan baik akan meningkatkan proses pembelajaran yang dapat diaplikasikan pada pekerjaan.

4. Hasil penilaian dampak pelatihan terhadap kinerja perusahaan tidak menunjukkan korelasi yang signifikan, hal ini disebabkan oleh beberapa faktor antara lain ketersediaan bahan baku dan hari kerja yang tersedia. Hasil penilaian dari rasio pendapatan dengan biaya produksi diperoleh sebagai berikut: 3,87 tahun $2009,4,15$ tahun $2010,5,76$ tahun 2011, 5,24 tahun 2012 dan 4,76 tahun 2013.

5. Hasil penilaian dampak biaya pelatihan terhadap pendapatan diperoleh hasil sebagai berikut: tahun 2009 dengan biaya pelatihan Rp. 52.076.000,pendapatan perusahaan Rp. 1.588.011.000.000,-, tahun 2010 dengan biaya pelatihan Rp. 57.925.000,pendapatan perusahaan Rp. 1.419.415.000.000,-, tahun 2011 dengan biaya pelatihan Rp. 70.502.000,pendapatan perusahaan Rp. 2.180.354.000.000,-, tahun 2012 dengan biaya pelatihan Rp. 88.392.000,pendapatan perusahaan Rp. 2.703.109.000.000,-, dan tahun 2013 dengan biaya pelatihan Rp. 
117.272.000,- pendapatan perusahaan Rp. 2.664.111.000.000,-.

\section{DAFTAR PUSTAKA}

1. Arikunto, Suharsimi, (2013), Prosedur Penelitian: suatu pendekatan praktik. Rineka Cipta. Jakarta.

2. Bambang Wahyudi, (2002), Manajemen Sumber Daya Manusia, Sulita, Bandung.

3. Beti Nasution, (2006), Pelatihan Sumberdaya Manusia Berbasis Kompetensi, Jurnal Analisis Administrasi dan Kebijakan, Vol. 3, No. 1.

4. Dessler, Gary (2000), Manajemen Personalia, Prehalindo. Jakarta.

5. Dimyati, dan Mudjiono, (2009), Belajar dan Pembelajaran. Jakarta: Rineka Cipta.

6. Gomes, Faustino Cardoso, (2003), Manajemen Sumber Daya Manusia, Penerbit Andi, Yogyakarta.

7. Handoko, T. Hani. (2003), Manajemen Personalia dan Sumber Daya Manusia. Edisi Kedua. Cetakan Kesebelas. Badan Penerbit Fakultas Ekonomi. Yogyakarta.

8. Hardjana, A. M. (2001), Training SDM yang Efektif, Yogyakarta: Kanisius.

9. Kaswan, (2011), Pelatihan dan Pengembangan untuk Meningkatkan Kinerja SDM, Alfabeta, Bandung.

10. Khan, R. A. G., (2011), Impact of Training and Development on Organizational Performance, Global Journal of Management and Business Research Vol. 2, ISSN 0975-5853 Issue.

11. Kirkpatrick, D. L., \& Kirkpatrick, J. D. (2005). Transferring learning to behavior: Using the four levels to improve performance. San Fransisco: Berrett-Koehler Publishers.

12. Kotler, Philip. (2005), Manajamen Pemasaran, Jilid 1 dan 2. Jakarta: PT. Indeks Kelompok Gramedia.

13. Laporan Tahunan PT. Pupuk Iskandar Muda (2012)

14. Laporan Tahunan PT. Pupuk Iskandar Muda (2013)

15. Mangkunegara, A.A. Anwar Prabu, (2000), Manajemen Sumber Daya Manusia Perusahaan. PT. Remaja Rosdakarya. Bandung.

16. Mangkunegara, Anwar Prabu. (2003), Perencanaan dan Pengembangan Sumber Daya Manusia. Bandung: Refika Aditama.

17. M. Manullang, (2001), Manajemen Personalia, Yogyakarta: Gajah Mada University Press.

18. M. Manullang, (2004), Dasar-dasar Manajemen, Yogyakarta: Gajah Mada University Press.

19. Nasution, Harmein. (2008), Proses Pengelolaan Sumber Daya Manusia, USU Press, Medan.

20. Rivai, Veithzal, (2004), Manajemen Sumber Daya Manusia Untuk Perusahaan. Cetakan Pertama. PT. Raja Grafindo. Jakarta.
21. Robert L. Mathis, John H. Jackson, (2008), Human Resource Management, Mason: South Western.

22. Saadat U. Kirmani, (2013), Training Human Resources An Evidence From Pakistan, Interdisciplinary Journal Of Contemporary Research In Business Vol 4.

23. Sinulingga, Sukaria. (2012). Metode Penelitian. USU Press. Medan.

24. Velada \& Caetano, (2007), The effects of training design, individual characteristics and work environment on transfer of training, International Journal Of Training and Development, ISSN 13603736. 